\title{
A Numerical Bubbly Flow Investigation of Drag Reduction for Underwater Vehicles
}

Moschny, S., Monir, S and Jones, M.

This is a paper presented at the 7th IEEE Int. Conference on Internet Technologies and Applications ITA-17, Wrexham, UK, 12-15 September 2017.

Copyright of the author(s). Reproduced here with their permission and the permission of the conference organisers.

\section{Recommended citation:}

Moschny, S., Monir, S and Jones, M. (2017) 'A Numerical Bubbly Flow Investigation of Drag Reduction for Underwater Vehicles'. In: Proc. 7th IEEE Int. Conference on Internet Technologies and Applications ITA-17, Wrexham, UK, 12-15 September 2017, pp. 194-198. doi: 10.1109/ITECHA.2017.8101937 


\title{
A Numerical Bubbly Flow Investigation of Drag Reduction for Underwater Vehicles
}

\author{
Sven Moschny, Shafiul Monir, Martyn Jones \\ School of Applied Science, Computing and Engineering, \\ Glyndwr University, Plas Coch, Mold Road, \\ Wrexham, LL11 2AW, UK
}

\begin{abstract}
This paper discusses the numerical investigation of dispersed bubbly flow within the boundary layer of a fully submerged axisymmetric body in horizontal position. The aim is to analyse the influence of injection position and bubble parameters on the drag reduction behaviour. The numerical study is conducted with the commercial CFD package ANSYS Fluent using the Eulerian-Eulerian modelling approach. Several sets of simulations are carried out with air injection velocities in the rage of $1 \mathrm{~m} / \mathrm{s}$ to $15 \mathrm{~m} / \mathrm{s}$, injection locations between 0 and $0.5 \mathrm{~m}$, and bubble diameters from $0.1 \mathrm{~mm}$ to $2 \mathrm{~mm}$. In order to obtain the percentage drag reduction the results are correlated with a model without air injection. The simulations demonstrate a different behaviour between small and large bubble diameters of $0.1 \mathrm{~mm}$ and $2 \mathrm{~mm}$ respectively. Small bubbles archive drag reduction rates around $10 \%$ almost independent from the injection velocity and position, while large bubbles are highly affected by those parameters. The maximum drag reduction of $20.67 \%$ is achieved by injecting bubbles of $2 \mathrm{~mm}$ diameter with a velocity of $12.5 \mathrm{~m} / \mathrm{s}$ at the tip of the prow nose. It is presented that the drag reduction increases with increasing injection velocity and bubble diameter. These parameters enable the bubbles to build up a continuous film across large parts of the hull which is required for a sufficient drag reduction.
\end{abstract}

Keywords-Eulerian-Eulerian approach; multiphase flow; bubble drag reduction; axisymmetric body; CFD

\section{INTRODUCTION}

Since the first time, humans used vessels to move over water, technical improvement became a perpetual process. Over centuries, vessels evolved from simple dugout canoes up to modern nuclear powered submarines. First merchant ships lay the foundation for intercontinental trade and global markets. Driven by the increasing demand for commodities, maritime transport becomes more and more important. Up to $80 \%$ of the global trade by volume is moved by the maritime shipping industry, a total of 9.84 billion tons in 2014 [1].

With the increase of global maritime trade and seafaring in general, more and more energy is required to fuel them. This lead to a vast emission of greenhouse gases, as the majority of seafaring vessels is powered by fossil fuels. With around 960 million tonnes of $\mathrm{CO} 2$, the international shipping emits about $2.5 \%$ of the total greenhouse gas pollution worldwide [2]. To accomplish the international agreement to reduce greenhouse gases, new energy saving techniques are of great importance.
Reducing the drag of the vessel will lead to a decreased energy consumption. The skin friction drag contribution of the total drag is $60-70 \%$ for cargo ships, $80 \%$ for tankers [3] and up to $90 \%$ for submarines [4]. Over the last decades, different skin friction reduction technologies were the subject of many investigations. Some approaches like polymers, coatings, surfactants and microbubbles have shown significant influence on drag behaviour of vessels [5]. Injecting microbubbles in the turbulent boundary layer between hull and water is a promising technique to decrease the skin friction drag. Studies in this field archived drag reduction rates up to $80 \%$ [6]. This study is motivated by the contribution to this research field and further exploration of microbubble skin fraction reduction.

This numerical study investigates multiphase flows in order to reduce skin friction drag by inducing microbubbles in the turbulent boundary layer of a fully submerged axisymmetric body. Various multiphase flow issues are omnipresent in many ordinary engineering applications like pump systems, pipeline transportation, hydraulic machines or seafaring. Despite the wide range of investigations conducted by many scientists, there is no clearly established theory for the fundamental skin friction reduction mechanisms of bubbly flow. This work aims to contribute to this complex research field of multiphase flow and deliver recommendations in order to achieve a sufficient bubble drag reduction.

\section{GOVERNING EQUATIONS}

In order to describe and predict the detailed behaviour of multiphase flows, numerical models are used for flow simulations with the commercial CFD package ANSYS Fluent. There are various models available with different limits and different computational effort which are suitable for various multiphase flow issues.

In the Euler-Euler approach, both phases are considered as fluid, therefore, it is also called multi-fluid model. The dispersed phase is treated as a second continuous phase which interacts and interpenetrates with the continuous phase. For each individual phase, a set of conservation equations are solved. As the phases are treated as continua, the equations have similar structures, which lowers the computational effort, independent from the volume fraction of the single phases. The following three multiphase flow models are available in the Euler-Euler approach [7]. 
The mixture model is a simplified multiphase model where the phases are interpenetrating. It is used in various applications like flows with phases moving at different speeds, homogenous multiphase flows with strong coupling and for non-Newtonian viscosity. The equations of momentum, continuity and energy conservation are solved for the mixture, the equations of volume fraction for all secondary phases and if phases are moving at various speeds, the algebraic expressions for the relative velocities [7].

Continuity equation:

$$
\frac{\partial \rho}{\delta t}+\nabla(\rho u)=0
$$

where $\rho$ is the density, $u$ is the particle velocity.

Momentum equation:

$$
\frac{\partial \rho u}{\delta t}+\nabla(\rho u u)=-\nabla p+\nabla \tau+\rho g
$$

where $p$ is the fluid pressure, $\tau$ is the viscous stress tensor and $g$ is the gravity vector.

\section{SIMULATION}

\section{A. Model}

The numerical implementation is similar to the test body utilized in an experiment by Huang et al. [8]. The nose is elliptically shaped, while the middle section is parallel and the aft is a tangential ogive. The detailed dimension of the $3.066 \mathrm{~m}$ long underwater vehicle are illustrated in Fig. 1. The axisymmetric hull shape is based on a standard Defence Research Establishment Atlantic (DREA) submarine bare hull [9].

\section{B. Boundary Conditions}

In this work, the SIMPLE pressure-velocity coupling scheme is used with second order upwind schemes for all calculations except the pressure, where a standard scheme is applied. The transient formulation is set to second order implicit. Virag et al. [10] reported that the time step $(\Delta t)$ of $0.0001 \mathrm{~s}$ was found to give accurate results for all computed velocities. This setting was also adopted in the simulation of Shereena et al. [11], hence $\Delta \mathrm{t}=0.0001 \mathrm{~s}$ used in all calculations with this study. Exactly like both mentioned studies [10], [11], the characteristic area was represented by $\mathrm{V}^{2 / 3}$ with a total body volume of $\mathrm{V}=0.148 \mathrm{~m}^{2}$. The Eulerian multiphase model with implicit volume fraction formulation and the standard k-epsilon viscous model was chosen. Standard wall functions were defined for the near wall treatment. The first order implicit transit formulation showed a more stable convergence behaviour than the second order implicit formulation and was therefore utilized in all multiphase calculations. In addition to the primary phase (water) a secondary phase (air) was defined with constant surface tension coefficient of $0.0735 \mathrm{~N} / \mathrm{m}$. The volume fraction was set to 1 at the air inlet and to 0 at the water inlet.

Fig. 2 illustrates the computational domain, designed with the following boundary conditions: The Air Inlet (A) is defined as velocity-inlet type with a velocity magnitude (Uair) between $1 \mathrm{~m} / \mathrm{s}$ and $15 \mathrm{~m} / \mathrm{s}$, dependent on the particular simulation. The Outlet (B) is defined as outflow. The Wall (C) is set to stationary wall with specific shear stress of 0 pascal for the $x$ - and $y$-component. Wall roughness height and constant remain on the default values. The Water (D) is of interior type. The Hull (E) is a stationary wall with no slip condition. The Inlet $(\mathrm{F})$ is set to velocity-inlet type with a velocity magnitude (U) of $2.152 \mathrm{~m} / \mathrm{s}$ in x direction. Suggested

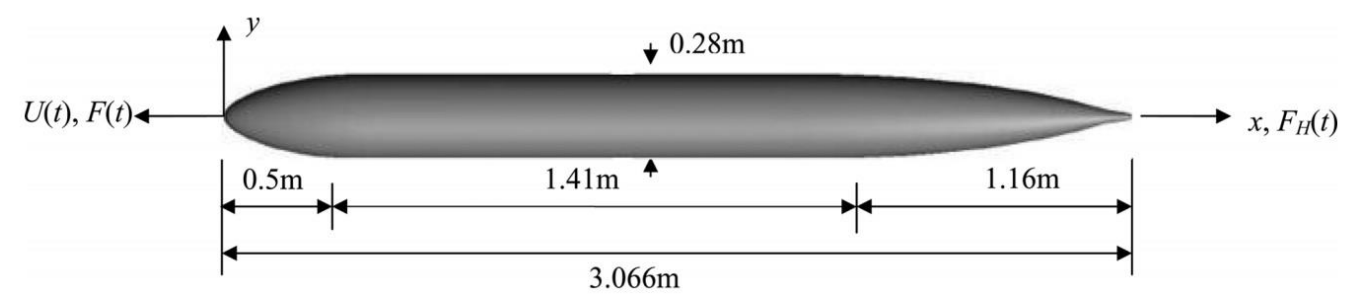

Fig. 1. Dimension of the submerged body [10].

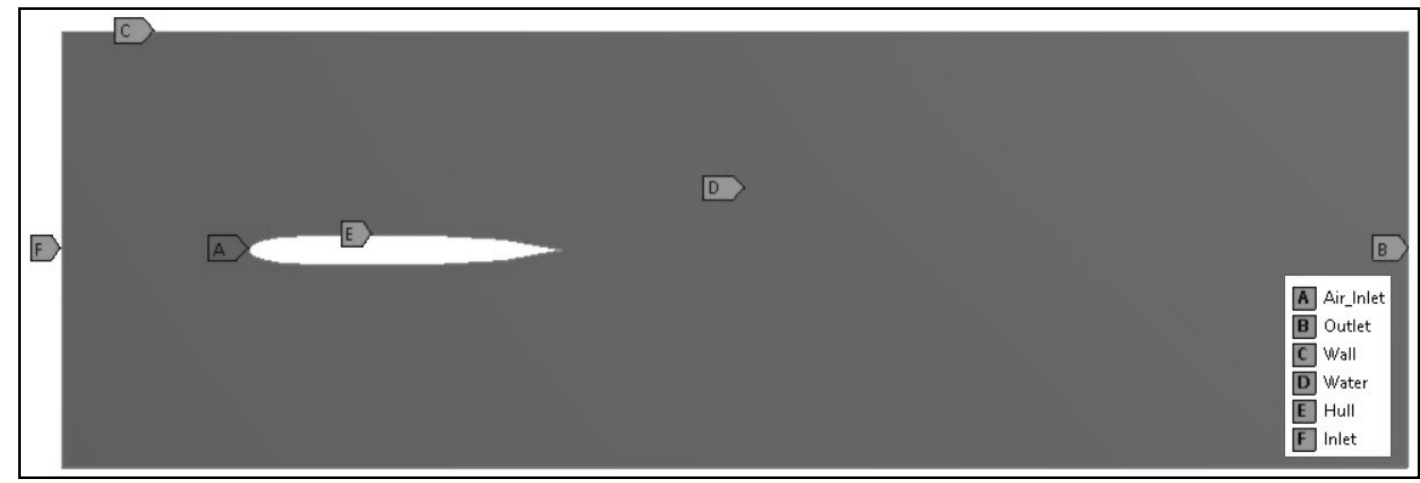

Fig. 2. Computational domain. 


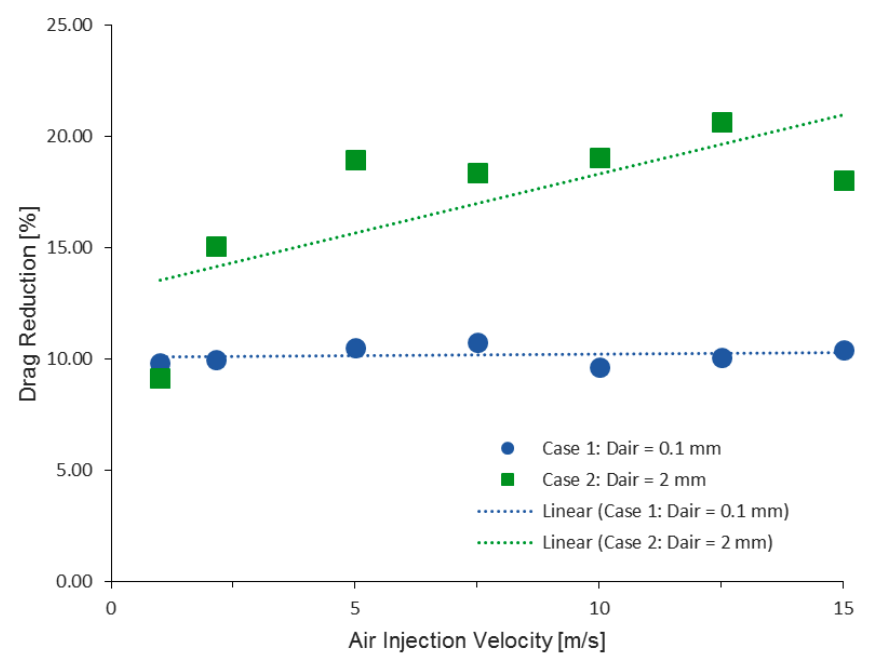

Fig. 3. Comparison of Case 1 and Case 2: Injection velocities.

by Sarkar et al. [12] the representative values of turbulent intensity is chosen 5\% and length scale, 0.003066 which represents $0.001 * \mathrm{~L}$, where the length of the body (L) is given with $3.066 \mathrm{~m}$.

\section{Cases}

In the multiphase flow simulations, the influence of several factors on the drag properties are analysed in three steps. In the first step, the injection velocities of $U_{\text {air }}=1 \mathrm{~m} / \mathrm{s}$, $2.152 \mathrm{~m} / \mathrm{s}, \quad 5 \mathrm{~m} / \mathrm{s}, \quad 7.5 \mathrm{~m} / \mathrm{s}, \quad 10 \mathrm{~m} / \mathrm{s}, \quad 12.5 \mathrm{~m} / \mathrm{s}, \quad 15 \mathrm{~m} / \mathrm{s}$ are computed with constant injector position and bubble diameter. In the second step, injector distances of $X_{\text {air }}=0 \mathrm{~mm}, 100 \mathrm{~mm}$, $200 \mathrm{~mm}, 300 \mathrm{~mm}, 400 \mathrm{~mm}, 500 \mathrm{~mm}$ from the tip of the prow nose are analysed. The injection velocity and bubble diameter are kept constant. In the third step, the bubble diameters of $\mathrm{D}_{\text {air }}=0.1 \mathrm{~mm}, 0.5 \mathrm{~mm}, 0.75 \mathrm{~mm}, 1 \mathrm{~mm}, 1.5 \mathrm{~mm}, 2 \mathrm{~mm}$ are computed with constant air velocity and injection position. For every step, the parameters build on the highest drag reduction result of the previous step. The three steps are conducted for two cases, where the highest result of Case 1 is the initial condition for Case 2.

\section{RESULTS}

\section{A. Influence of Injection Velocity}

The achieved drag reductions relative to the injection velocities of both cases are plotted in the graph, illustrated in Fig. 3. The bubble diameters for Case 1 and Case 2 are $0.1 \mathrm{~mm}$ and $2 \mathrm{~mm}$, respectively. For both cases, the bubbles are injected at the foremost position. The resulting drag reductions of Case 1 shows an almost horizontal trend around $10 \%$, indicating that the various air injection velocities have nearly no influence on the drag reduction. In contrast, Case 2 shows an increasing drag reduction trend with increasing air injection velocity, where the course rises from around $10 \%$ to around $20 \%$. This data leads to the conclusion, that with a larger air diameter, the influence of air velocity on the drag reduction behaviour increases. A high drag reduction is only possible, if a sufficient air volume fraction is present in the

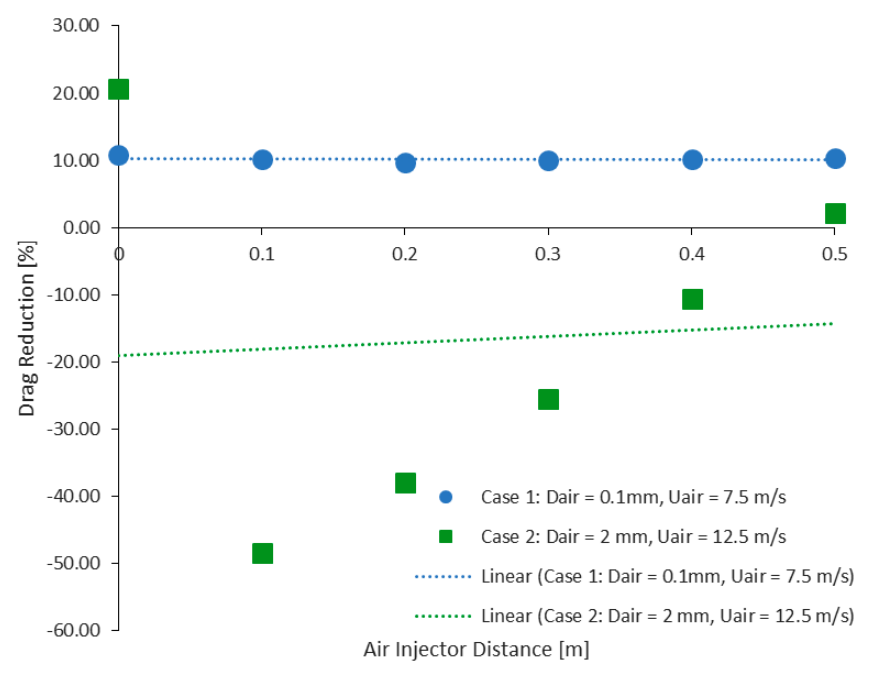

Fig. 4. Comparison of Case 1 and Case 2: Injector positions.

boundary layer. With a small bubble diameter, no continuous bubble film builds up and hence only minor drag reduction is attainable for all simulated injector velocities. While with larger bubble diameter, the drag reduction increases together with the injection velocity as larger hull sections are covered with bubbles.

\section{B. Influence of Injector Position}

The achieved drag reductions relative to the injector distances of both cases are plotted in the graph, illustrated in Fig. 4. Case 1 comprises a bubble diameter of $0.1 \mathrm{~mm}$ and an injection velocity of $7.5 \mathrm{~m} / \mathrm{s}$, while Case 2 comprises a bubble diameter of $2 \mathrm{~mm}$ with an injection velocity of $12.5 \mathrm{~m} / \mathrm{s}$. The drag reduction results of both cases show a nearly horizontal linear trend line, with only minor growth within Case 2 . While all results of Case 1 are around $10 \%$ drag reduction, the linear overall trend of Case 2 is around $-20 \%$. This value is caused by negative drag reduction at injector positions from $0.1 \mathrm{~m}$ to $0.4 \mathrm{~m}$. The data implies that the injector position influences

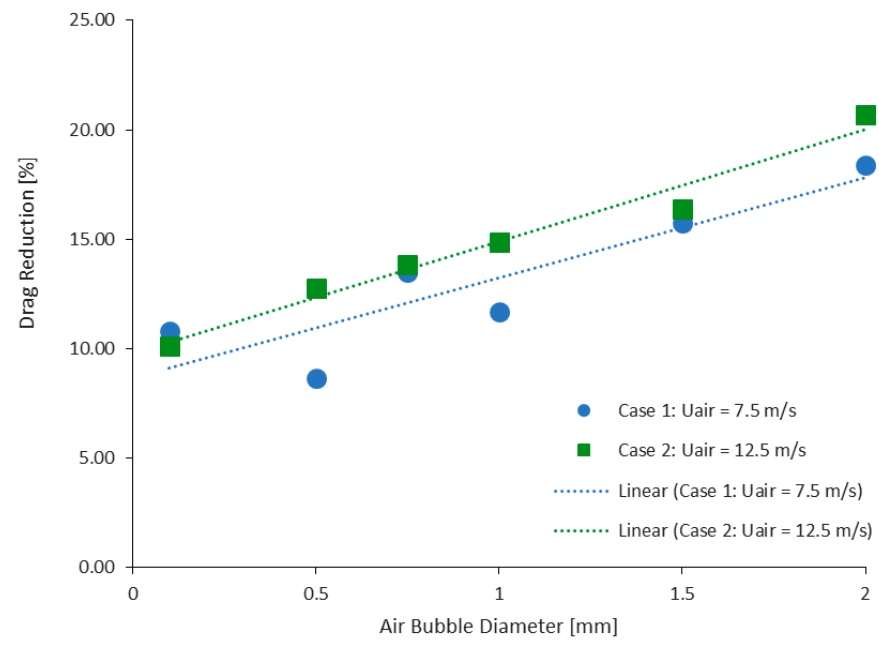

Fig. 5 Comparison of Case 1 and Case 2: Bubble diameters. 
the drag behaviour only at larger air diameter and higher injection velocities. Where only an injection at the tip of the prow nose or at the transition between nose and middle body results in any drag reduction. With small bubble diameters and moderate velocities, the injector location's effect on the drag reduction becomes less important as all positions result in a reasonable drag reduction, while the general trend is similar to the case with larger bubbles. Both case studies agree with the overall outcome, that the optimum injector position is at the tip of the prow nose. Injection at the rounding of the nose leads to less drag reduction and on the contrary, drag may even increase. The injection position between nose and middle body may lead to a moderate drag reduction but less effective than the foremost position. The superior injection at the front can also be explained with a fully developed air bubble film which is maintained over the whole nose and large parts of the middle body, while at other injector positions, only parts of the nose are enveloped in bubbles.

\section{Influence of Bubble Diameter}

The achieved drag reductions relative to the injector distances of both cases are plotted in the graph, illustrated in Fig. 5. The injection velocities for Case 1 and Case 2 are $7.5 \mathrm{~m} / \mathrm{s}$ and $12.5 \mathrm{~m} / \mathrm{s}$, respectively. For both cases, the bubbles are injected at the foremost position. The resulting drag reductions for Case 1 and Case 2 show a similar linear run. In both cases, the drag reduction is rising with increasing bubble diameter. In the first trend, the reduction rate grows from around $9 \%$ to more than $18 \%$ and in the second trend from around $10 \%$ to more than $20 \%$. The only difference between Case 1 and Case 2 is the injection velocity of $7.5 \mathrm{~m} / \mathrm{s}$ and $12.5 \%$, respectively. The result shows that the bubble diameter is direct related to the drag reduction, independent from the injection velocity. However, higher velocities tend to achieve stronger reduction in drag.

\section{CONCLUSION}

Various bubble parameters and injection positions were analysed and lead to the conclusion that small bubbles of $0.1 \mathrm{~mm}$ diameter are less effected by injection velocity or position as all configurations resulted in a moderate drag reduction around $10 \%$. In contrast, large bubbles of $2 \mathrm{~mm}$ diameter are strongly influenced by the injection velocity and positions as the simulations result in either strong drag reduction up to $20.67 \%$ or even an increase in drag. The analysis shows that it is necessary to maintain a bubble film across large parts of the hull surface in order to obtain a sufficient drag reduction. The best result was achieved with bubbles injected at high volumetric flow rate, which is a function of injection velocity and air diameter, at the tip of the prow nose.

\section{REFERENCES}

[1] UNCTAD, Review of Maritime Transport 2015. New York, Geneva: United Nations, 2015.

[2] International Maritime Organization, Third IMO Greenhouse Gas Study 2014. International Maritime Organization, London, 2015.

[3] K. Fukuda, J. Tokunaga, T. Nobunaga, T. Nakatani, T. Iwasaki, and Y. Kunitake, "Frictional drag reduction with air lubricant over a superwater repellent surface," Journal of Marine Science and Technology, vol. 5, no. 3, pp. 123-130, Dec. 2000.

[4] M. Gad-el-Hak, "Introduction to flow control," in Flow Control: Fundamentals and Practices, M. Gad-el-Hak, A. Pollard, and J.-P. Bonnet, Eds. Berlin: Springer, 1998, pp. 1-107.

[5] V.-T. Truong, "Drag reduction technologies," DSTO Aeronautical and Maritime Research Laboratory, Fishermans Bend, Australia, Report DSTO-GD-0290, 2001.

[6] P.V. Skudarnov, and C.X. Lin, "Drag reduction by gas injection into turbulent boundary layer: Density ratio effect," International Journal of Heat and Fluid Flow, vol. 27, no. 3, pp. 436-444, June 2006.

[7] ANSYS, Inc., ANSYS Fluent Theory Guide. Canonsburg, PA: ANSYS, Inc., 2013.

[8] T. Huang, N. Santelli, and G. Belt, "Stern boundary-layer flow on axisymmetric bodies," in Proc. 12th Symp. on Naval Hydrodynamics, Wash, D.C., 5-9 June 1978, pp. 125-167.

[9] C. Baker, "Estimating drag forces on submarine hulls," Defence R\&D Canada - Atlantic, Dartmouth, NS, Contract Report CR 2004-125, Sept. 2004.

[10] M. Virag, S. Vengadesan, and S.K. Bhattacharyya, "Translational added mass of axisymmetric underwater vehicles with forward speed using Computational Fluid Dynamics," Journal of Ship Research, vol. 55, no. 3, pp. 185-195, Sept. 2011.

[11] S.G. Shereena, S. Vengadesan, V.G. Idichandy, and S.K. Bhattacharyya, "CFD study of drag reduction in axisymmetric underwater vehicles using air jets," Engineering Applications of Computational Fluid Mechanics, vol. 7, no. 2, pp. 193-209, 2013.

[12] T. Sarkar, P.G. Sayer, and S.M. Fraser, "Flow simulation past axisymmetric bodies using four different turbulence models," Applied Mathematical Modelling, vol. 21, no. 12, pp. 783-792, Dec. 1997. 